\title{
Prediction of survival with the changing pattern of vital sign in terminally ill cancer patients
}

\section{Se-ll Go ${ }^{1}$, Jung Hun Kang}

1Department of Internal Medicine, Gyeongsang National University Changwon Hospital, Gyeongsang National University School of Medicine, Institute of Health Sciences, Changwon, Republic of Korea

${ }^{2}$ Department of Internal Medicine, Gyeongsang National University School of Medicine, Institute of Health Sciences, Jinju, Republic of Korea

\section{Background}

Prediction of survival is of great concern to terminally ill cancer patients and their family. Inaccurate prediction of survival results in unnecessary and potentially harmful therapies, prolongs hospitalization, and hinders patients from planning their remaining life. Treating physicians often rely on symptomatic change to predict survival of patients and tend to overestimate the remaining survival. Several prediction tools and scoring systems developed to overcome the inaccuracy of clinical estimation are rather complex to use easily by physicians. Therefore, objective and simple prediction model is needed to identify the patients who benefit from early palliative care.

\section{Methods}

Design and period: retrospective study (Oct. 2009 Dec. 2013)

\section{Eligibility}

Patients with advanced cancer who died at the regional cancer center of Gyeongsang National University Hospital during the study period

Not treated with chemotherapy during the last 6 weeks of life At least one or more vital signs [systolic blood pressure (SBP), diastolic blood pressure (DBP), heart rate $(\mathrm{HR})$, respiratory rate (RR), body temperature (BT)] obtained during the last 8 days

\section{Study objectives and definitions}

Changes in vital signs over time during the last 8 days of life Differences of the average vital signs between day $0-3$ (within 3 days) and day 3 - 8 (over 3 days) before death Impact of 'vital sign risks' on survival prediction

'Vital sign risk' was considered to be present if the daily average change of vital sign compared to the average vital sign of day 3 - 8 (over 3 days) before death meets the following criteria: SBP decrease $\geq 10 \mathrm{mmHg}$, DBP decrease $\geq 10 \mathrm{mmHg}$, HR increase $\geq 10 \mathrm{BPM}, \mathrm{RR}$ increase $\geq 5 \mathrm{RPM}$, and $\mathrm{BT}$ increase $\geq 0.5^{\circ} \mathrm{C}$

\section{Results}

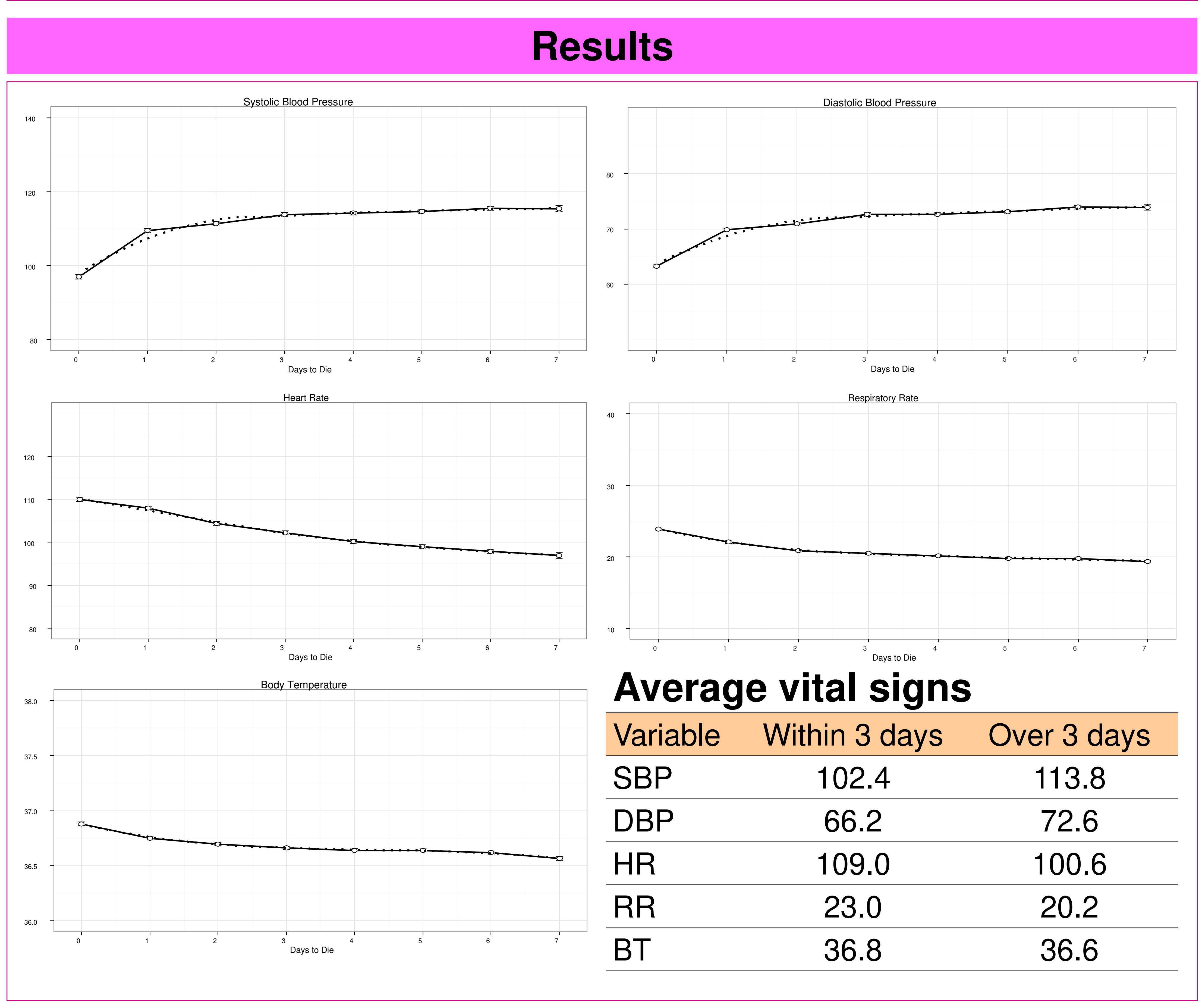

Risk of death within 3 days according to the vital sign risk

\begin{tabular}{|c|c|c|c|c|}
\hline \multirow{2}{*}{ Vital sign risk } & \multirow{2}{*}{ within 3 days } & \multicolumn{2}{|c|}{ over 3 days } & \multirow{2}{*}{ Matched OR $(95 \% \mathrm{Cl})$} \\
\hline & & present & Absent & \\
\hline \multirow[t]{2}{*}{ SBP dec. $\geq 10 \mathrm{mmHg}$} & Present & 259 & 601 & $6.5(5.2-8.1)$ \\
\hline & Absent & 93 & 278 & \\
\hline \multirow[t]{2}{*}{ DBP dec. $\geq 10 \mathrm{mmHg}$} & Present & 87 & 587 & $11.1(8.4-15.0)$ \\
\hline & Absent & 53 & 504 & \\
\hline \multirow[t]{2}{*}{ HR inc. $\geq 10$ BPM } & Present & 261 & 517 & $5.9(4.7-7.5)$ \\
\hline & Absent & 87 & 366 & \\
\hline \multirow[t]{2}{*}{ RR inc. $\geq 5$ BPM } & Present & 38 & 430 & $14.8(10.2-22.4)$ \\
\hline & Absent & 29 & 734 & \\
\hline \multirow[t]{2}{*}{ BT inc. $\geq 0.5^{\circ} \mathrm{C}$} & Present & 64 & 309 & $3.4(2.7-4.3)$ \\
\hline & Absent & 91 & 767 & \\
\hline \multirow[t]{2}{*}{2 of 5 vital signs } & Present & 265 & 748 & $15.6(11.6-21.3)$ \\
\hline & Absent & 48 & 170 & \\
\hline \multirow[t]{2}{*}{3 of 5 vital signs } & Present & 72 & 653 & $17.6(12.7-25.3)$ \\
\hline & Absent & 37 & 469 & \\
\hline \multirow[t]{2}{*}{4 of 5 vital signs } & Present & 12 & 362 & $25.9(15.2-47.8)$ \\
\hline & Absent & 14 & 843 & \\
\hline \multirow[t]{2}{*}{5 of 5 vital signs } & Present & 3 & 178 & $35.6(15.0-111.0)$ \\
\hline & Absent & 5 & 1045 & \\
\hline
\end{tabular}

Sensitivity, specificity, and positive predictive value for the probability of death within 3 days according to the vital sign risk

\begin{tabular}{llll}
\hline & Sensitivity $(95 \% \mathrm{Cl})$ & Specificity $(95 \% \mathrm{Cl})$ & $\begin{array}{c}\text { Positive predictive } \\
\text { value }(95 \% \mathrm{Cl})\end{array}$ \\
\hline SBP dec. $\geq 10 \mathrm{mmHg}$ & $0.699(0.672-0.724)$ & $0.714(0.688-0.739)$ & $0.902(0.882-0.920)$ \\
\hline DBP dec. $\geq 10 \mathrm{mmHg}$ & $0.548(0.520-0.575)$ & $0.886(0.867-0.903)$ & $0.927(0.906-0.944)$ \\
\hline HR inc. $\geq 10 \mathrm{BPM}$ & $0.632(0.605-0.659)$ & $0.717(0.692-0.742)$ & $0.899(0.878-0.918)$ \\
\hline RR inc. $\geq 5 \mathrm{BPM}$ & $0.380(0.354-0.408)$ & $0.946(0.932-0.957)$ & $0.942(0.918-0.959)$ \\
\hline BT inc. $\geq 0.5{ }^{\circ} \mathrm{C}$ & $0.303(0.278-0.329)$ & $0.874(0.854-0.892)$ & $0.804(0.765-0.838)$ \\
\hline 2 of 5 vital signs & $0.823(0.801-0.843)$ & $0.746(0.721-0.769)$ & $0.955(0.941-0.966)$ \\
\hline 3 of 5 vital signs & $0.589(0.561-0.616)$ & $0.911(0.894-0.926)$ & $0.951(0.934-0.965)$ \\
\hline 4 of 5 vital signs & $0.304(0.279-0.330)$ & $0.979(0.969-0.986)$ & $0.964(0.940-0.978)$ \\
\hline 5 of 5 vital signs & $0.147(0.128-0.168)$ & $0.994(0.987-0.997)$ & $0.973(0.939-0.989)$
\end{tabular}

A total of 1,357 patients were included. Mean SBP and DBP abruptly decreased during the last day of life. Mean RR apparently increased since 2 days before death. Mean HR consistently increased and there was small difference of mean BT during the last 8 days of life. The matched odds ratios for death within 3 days were $6.5,11.1,5.9,14.8$, and 3.4 in SBP, DBP, HR, RR, and BT, respectively, compared with their counterparts. The positive predictive values for death within 3 days were $90.2 \%, 92.7 \%, 89.9 \%, 94.2 \%$, and $80.4 \%$ in SBP, DBP, HR, $\mathrm{RR}$, and $\mathrm{BT}$, respectively. The combined use of vital sign risks increased the positive predictive value up to $97.3 \%$.

\section{Conclusion}

The change patterns of vital signs are insensitive to predict the impending death within 3 days, but may be useful to differentiate it from temporary deterioration due to the high positive predictive value in terminally ill cancer patients. A prospective study is warranted to validate these results. 